\title{
Socio-Economic Background Of Households and Health Status of Young Children (3-5 Years of Age) "A Case Study of Village Battle-Ballian, Udhampur"
}

\author{
Sharief Ahmed \\ Mphil scholar University of Jammu.
}

\begin{abstract}
Existing literature suggests that health status is multi-dimensional; a result of complex causes such as socio-demographic factors (household amenities, food intakes of child, overall hygiene of the child, immunization status), environmental, genetic and biomedical factors and varies over the life cycle, implying intergenerational health effects. Studies show that health in early life has substantial effects on health and wellbeing throughout the entire life course. Literature shows that better-off people both socially and economically tend to be in better health and healthier people are more productive. Studies on intergenerational transmission of health report positive correlation between favorable maternal characteristics and survival probabilities of their children. Recognizing the multiplicity of pathways, the bidirectional nature of causes and effects between health status and economic development, it is quite possible to attempt a review on socioeconomic background of the household and health status of young children (36 months to 71 months) issues in one study. This study therefore focuses on the effects of parental socio-economic status (SES) on child health. Main focus of this paper is to find the effect of socio-economic background of the household as an indicator of SES and examine its impact on child health outcomes for children aging 3 to 5 years. Socio-economic status of household affects child development and better health as well as child development contribute to Economic Development of an Economy.
\end{abstract}

Keywords: Socio-economic status (SES), Health status, Households, Young Childrens

\section{Introduction}

"Health is a state of complete physical, mental and social well-being and not merely the absence of disease or infirmity".W.H.O

There is a very common and true saying that Health is Wealth. We should always keep in mind that wealth is wealth however health is the greatest wealth in this world. A child is the future of the mankind, since the origin of the mankind on this planet Earth. Children are assumed to be the real assets of a family. Household socio economic factors vary across families and nations. The health of children at household level is considered to be significant as far as economic and social contribution is concerned, particularly in the developing and low income countries. Every mother properly takes care of her child whether the child is male or female, a child is a child for his/her mother so, mother equally considered her child health i.e. food intakes, immunization and also the care of her child during pregnancy. Mothers are generally considered as the care taker of her child. Health of children varies as the livelihood or the income of the household is concerned. Whereas there is general perception that health of children is less in the poor families as compared with their counterpart. In most of the cases children are assumed to produce future services to the parents and a source of emotional satisfaction for them. It is generally seen that there is steep variation in health of children in rural and urban areas. Poor people may indeed to spend less on children health production (Nutritional intake, immunization, pre and post natal checkups, hygiene of the child, safe drinking water, sanitation, etc) and may not be all that irrational in health care so, they are less likely to realize the aspiration that motivated them to have better health of children. Education of the parents is the most important factor in determining the care of children. The educated people tend to take care of their children as compared to the uneducated counterpart.

Traditionally, family status variables such as socio-economic status and parents' level of education have been regarded as predictors of children health status. Increasingly, research have been suggested that, rather than having a direct association with children health status, socio-economic status and parental level of education is part of a larger constellation of psychological and sociological variables influencing children health outcomes. The literature also suggests that the level of education influence parents knowledge, beliefs, values, and goals about child rearing, so that a variety of parental behavior are indirectly related to children health status. For example, higher socio-economic status and high levels of education may enhance parents facility at becoming involved in their children health, and also enable parents to acquire and model social skills and problem-solving strategies conducive to children health. Thus, children whose parents have higher socioeconomic status and higher levels of education may have an enhanced regard for higher health status, more 
Socio-Economic Background Of Households and Health Status of Young Children (3-5 Years of ..

positive ability beliefs, a stronger work orientation, and they may use more effective learning strategies than children of parents with lower socio-economic status and lower levels of education. With this information, it is important to note that socio economic background are one of the most influential yet significantly underrated factors in their child health. Many of households have a focus on parents education, occupation or home background (like; family income, mother language, activities of the family. Socio-economic status remains a topic of great interest to those who study children development. This interest derives from a belief that high socio-economic status families can afford for their children an array of services, goods, parental actions, and social connections that potentially rebound to the benefit of children and a concern that many low socioeconomic status children lack access to those same resources and experiences, thus putting them at risk for developmental problems. The interest in socio-economic status as a global construct persists despite evidence that there is wide variability in what children experience within every socio-economic status level, despite evidence that the link between socio-economic status and child health.

There are several factors affecting the health of children. Some of the main factors are:-

Poverty, Education of parents, Cultural norms, Family income, Standard of living, Immunization status, Health status of Mothers.

Problems of the Area

- Juggi jumpdi residents and the migrants are creating slum in the area that create severe health and hygienic problems.

- Irregular and untimely power cut creates panic for the inhabitants.

- Improper medical facility and unavailability of required medical staff probe threat to the life of pregnant women and the accident cases as such in the emergency situation they have to approach Jammu city for treatment.

- Improper availability of food and other basic necessities grips panic to the low income people.

- Improper connectivity to the city.

\section{Objectives}

- To identify the various factors determining the health status of young children.

- To identify the social constraints in health status of young children.

- To study the impact of nutritional intake on health status of young children.

\section{Literature Review}

George K.A (2000) conducted a study on the pattern of anemia and its relation to nutritional status and dietary habits among 3633 preschool children of 108 selected Anganwadi centers in rural areas of Kerala State during the period 1996 to 1998 . Weight and height of children were taken for assessing their nutritional status. The percentage of anemic children among male and female children was 10.25 and 12.55 respectively and statistical analysis showed that female children were more susceptible to anemia Christine M. Olson (2001) in the study 'Nutrition and health outcomes associated with food insecurity and hunger' explores how food insecurity and hunger relate to health and nutrition outcomes in food-rich countries such as the United States. In low income school-age children from two large urban areas of the U.S, risk of hunger and hunger were associated with compromised 15 psychosocial functioning, controlling for maternal education and estimated household income. Susmita Bharati et al (2001) conducted a study 'Determinants of nutritional status of preschool children in India', it is to assess the spatial distribution of nutritional status of children of less than three years through Z-scores of weight-forage, height-for-age and weight-for-height using data collected by the National Family Health Survey (NFHS-2, 1998-99), India. The data show that there are gender differences and spatial variations in the nutritional status of children in India. All the variables were found to affect significantly the nutritional status of children. The weight-for-age and height-for-age scores showed a dismal picture of the health condition of children in almost all states in India Oyekale A.S and Oyekale T.O (2002) conducted a study entitled by 'Do mothers' educational levels matter in child malnutrition and health outcomes in Gambia and Niger?' this study analyzed the effect of mothers' educational levels on child malnutrition. The probit analysis reveals that attainment of secondary education by the mothers, urbanization, presence of pipe water, presence of mother and father at home, polio vaccination, ever breastfed and access to radio and television significantly reduce the probability of stunting, wasting and underweight, while infection with diarrhea, fever and age at first polio vaccine significantly increase it. Elangovan and Shanmugan (2002) analyses the immunization and nutritional status among children aged under five in a major district in India, it reveals that Children in rural areas in India die due to infectious and communicable diseases. This study was carried out to know the immunization status, nutritional status and to assess the levels of the mother's knowledge regarding immunization and nutritional diet. For those mothers who were well aware of the immunization and nutritional programmes, the children height and weight were well correlated against the mothers who were not aware of 
Socio-Economic Background Of Households and Health Status of Young Children (3-5 Years of ..

these programmes, whose children height and weight did not show significant correlation. The result showed that 16 percent of the children were under malnutrition. The knowledge regarding immunization does not seem to influence the family size. Raja ram et al (2003) conducted a study entitled by 'An analysis of childhood malnutrition in Kerala and Goa' revealed that the confounding factors that influence the nutritional status of children in these states. The results showed that the relative prevalence of underweight and wasting was high in Kerala, but the prevalence of stunting was medium. The study recommends more area-specific policies for the development of nutritional intervention programmes. Jyothi Lakshmi et al (2005) conducted a study entitled by 'Influence of nutrition and environment on morbidity profile of Indian preschool children. The investigation was undertaken to study the morbidity profile of preschool children in relation to the child and maternal factors. Nutritional status was assessed using standard methodologies. Morbidity profile was associated with various child and maternal factors using appropriate statistical tests. Age among the child factors and literacy status and living conditions among the environmental factors were found to be critical factors that influenced the health status of preschool children.. Smith (1998) conducted a research work on the association between the socioeconomic status and the variety of health outcomes over time. The aim of article is to represent the relation between the SES and the health status. The data uses the first three waves of Health and Retirement Survey, a representative national survey of 7702 household (13652 individual) containing person born between the 1931 and 1932. Research indicates a strong relationship between the level of household income and the self reported health status. Health shocks can affect the wealth accumulation involves the medical expenses related with the new health event. Further on the other hand, healthier people may able to do more work, leading to higher earning availability of private health insurance also significantly provides the immediate financial blow from the health shock. Good health is an outcome that people desire and higher wealth or income enables them to purchase much of it.. Dutton (1985) conducted a research work on socio-economic status and children health. The aim of the article is to explore the relation between the family income and the three common children's problem: ear diseases, hearing losses and vision problem. The survey is conducted in 1970-71 in two separate area of Washington D.C. It uses the regression analysis to explore the relation between the socio-economic status and the children health. The report analyzed that lowest rate of ear diseases occur slightly in higher income level than for the hearing loss or vision problem. While, all the three problems had a similar U-shaped relation to the income which persisted, independent of socio-economic, demographic and illness factor. Such problems are mostly founded in the young children and those who are living in crowded housing and poorer neighborhood. The article shed the light on the factor responsible for high rate of ear, hearing and vision problem.

\section{Methodology}

This study based on primary data carried out at Battal-Ballian comprises of 804 households a village of district Udhampur Jammu and Kashmir. The survey started with the listing of 804 households in the village and 52 households were chosen by purposive and multistage sampling. Since the data is collected with the personal contact method, the respondents were interviewed at their houses and the questions were put to them in the language in which they feel comfortable. The respondent is the mother of the identified child. The data was separately collected on various dependent and independent variables such as socio economic background of the households, educational attainment, health and sanitation condition of the family, food intakes of the child, occupation of the family, household amenities, immunization status, public provisioning of the basic amenities the household where there was more than one eligible respondent, each of the respondent was interviewed separately. The identified child falls under the age group of 36 months to 71 months. For simple data analysis simple statistical tools like averages, percentages are used .

\section{Findings and Conclusion of the Study}

The study has been carried out to analyze the effect of socio-economic background of households and health status of young children (36 months to 71 months) of age. The analysis based on the large sample (52 Households) can be easily generalized to the whole population.

In the present study, Various socio-economic factors such as parental education status, marriage, age of mother, occupation of mother, household amenities, drinking water facility, toilet facility, households durables items, etc and health practices regarding child as food intakes of the child, health hygiene of the child, immunization status of the child's, usual health status of child, deformity among child, child birth weight, breast feeding of child, sterilization of feeding bottle and health practices regarding mother of the child such as delivery place of child, prenatal checkups and postnatal checkups, mother bedridden time period, health status of mothers, drinking and smoking habits of parents, etc whether all these factors have any effect on the health of the child or not. Major findings reveal that over the time health status of children improves as there is an improvement in the living standard of the people in that area. As the level of education of women increase, the health status of children also improved. 
Socio-Economic Background Of Households and Health Status of Young Children (3-5 Years of ..

One of the main objectives of the study is to identify the various factors determining the health status of young children as study reveals that various factors which determine health status of the child are type of family, caste, employment status, education status, availability of Ration card facility, poverty, lack of information. However, health status of majority of the children is good because of the improvement in living standard of the people. Health status of the children also depends on health hygiene as proper immunization status and mostly immunization status of children is good. However, there is slightly worse health status among children of poor families. It is due to poverty or lack of awareness.

Another main objective of the study is to identify the social constraints in health of young children. The usual approach in studies of socialization is to look at the interaction among cultural values, social structure, religious values and child-training practices. The relationship between the individual and society has been described in different ways depending on whether the focus is on the individual or on society. Various social constraints which limit the health of children are status of family (whether family belong to General caste or Scheduled castes, religion), Religious constraints in food intakes of child as children of certain castes like Brahmins do not eat eggs and other related food items.

Another main objective of the study is to study the impact of nutritional intake on the health status of children. Better nutritional intake leads to the better health status of children. Fruits, eggs, curd, butter and milk are the important nutritional intakes for the health of children. After the detailed analysis of the study, it has been concluded that there is a positive effect of nutritional intakes of the children. Children who consume the entire nutritional intake possesses good health as compared to their counterpart.

\section{Policies Implications}

This study is also important for policies implementation related to child care and nutritional intake of children and mothers during and after pregnancy, and consequently child health that has implications for future health and economic outcomes. We need to find that determination of how parental socio-economic status influences child health can provide insights into how the health status of the future generation and hence economic prosperity associated with this generation can be targeted early in life to sway economic development in the desired path. Understanding the parental socio-economic variables that influence child health is important for policy especially in the design of maternal and reproductive health programs as well as other social and economic interventions. This is in recognition of the central role of child health in determining economic outcomes in later life, and hence a country's prospect of economic development. The literature on how investments in the health and wellbeing of reproductive age women, especially the pregnant, contributes to the health and economic well being of the next generation can provide valuable information to policy makers on how to influence future economic growth through health related interventions.

\section{Bibliography}

[1]. George K.A (2000), “Anaemia and nutritional status of preschool children in Kerala”, Indian Journal of Pediatrics, Vol.67 (8), pp.575-578.

[2]. Cutler, D.M., and A. Lleras-Muney. (2008), "Education and health: evaluating theories and evidence." In J.S. House, R.F. Schoeni, G.A. Kaplan, and H. Pollack, eds., The Health Effects of Social and Economic Policy, New York: Russell Sage Foundation.

[3]. Christine M. Olson (1999), "Nutrition and Health Outcomes Associated with Food Insecurity and Hunger," Journal of Nutrition, Vol.129, pp.521-524

[4]. Bharati. S, Pal M, Bharati P (2001), "Determinants of nutritional status of preschool children in India," Journal Biosocial Science, Vol. 40(6), pp.801-814.

[5]. Lily Yaa Appoh and Sturla Krekling (2001), "Maternal nutritional knowledge and child nutritional status in the Volta Region of Ghana", Journal of Tropical Pediatrics, Vol. 47(6), pp.350-355.

[6]. Nawal El-Sayed, Ashry Gad Mohamed, Leila Nofal, Ahmed Mahfouz, and Hamdy Abou Zeid (2001), "Malnutrition among Preschool Children in Alexandria, Egypt, Journal of Health Population and Nutrition," Vol. 19(4), pp.275-280.

[7]. Oyekale A.S and Oyekale T.O (2002), "Do mothers' educational levels matter in child Malnutrition and health outcomes in Gambia and Niger?" Department of Agricultural Economics, University of Ibadan, Nigeria.

[8]. Girma, Woldemariam and Timotiows Genebo (2002), "Determinants of Nutritional Status of Women and Children in Ethiopia". Calverton, Maryland, USA: ORC Macro.

[9]. Elangovan and Shanmugan (2002), "Immunization and nutritional status among children aged under five in a major district in India," Department of Statistics, Annamalai University.

[10]. Raja ram.S, T. S. Sunil and Lisa K. Zottarelli (2003), “An analysis of childhood malnutrition in Kerala and Goa," Journal of Biosocial sciences, Vol. 35, pp.335- 351, Cambridge University press, U.K.

[11]. Jyothi Lakshmi A, Begum. K, Saraswathi G and Prakash. J (2005), "Influence of Nutrition and Environment on Morbidity Profile of Indian Preschool Children," Malaysian Journal of Nutrition, Vol 11(2), pp. 121-132.

[12]. Smith, J. P. (1998), "The impact of SES on health over the life-course." Journal of Human Resources

[13]. Kover (1982), "Health status of children in U.S.A and use of medical care," Disease management in the American market, BMJ, 320: $563-6$.

[14]. Overpeck MD, Moss AJ, Hoffman HJ, Hendershot GE (1989), "A comparison of the childhood health status of normal birth weight and low birth weight infants." Public Health Rep 1989 January;104(1):58-70.

[15]. Paul Contoyannis, Dooley Martin (2003), “The Role Of Child Health And Economic Status In Educational, Health And Labour Market Outcomes In Young Adulthood," Department of Economics, McMaster University, Hamilton, Ontario L8S 4M4 
CANADA.

[16]. Currie Janet, Joshua Goodman, (2007), "Parental Socioeconomic Status, Child Health, and Human Capital," Economics Department, Columbia University, New York.

[17]. Dutton. D. B. (1989), “Overview, methodological critique, and reformulation. In J. P. Bunker,” D. S. Gomby, \& B. H. Kehrer (Eds.) Pathways to health (pp. 29-69). Menlo Park, CA: The Henry J. Kaiser Family Foundation.

[18]. Phelan.C, (1995), "Social conditions as the fundamental causes of disease." Journal of Health and Social Behavior 35(Extra Issue): $80-94$

[19]. John. J (1998), "School Adjustment in Sixth graders: Parenting transitions, Family climate, and Peer norm effects. Child Development." 1995; 66:430-445. 